\title{
Diagnostic and management strategies for congenital H-type tracheoesophageal fistula: a systematic review
}

\author{
Keerthika Sampat ${ }^{1} \cdot$ Paul D. Losty ${ }^{1,2}$ \\ Accepted: 29 December 2020 / Published online: 20 January 2021 \\ (c) The Author(s) 2021
}

\begin{abstract}
Background H type tracheoesophageal fistula (H-TEF) is a rare congenital anomaly. Management may be complicated by late diagnosis and variation(s) in the therapeutic strategy. A systematic review of published studies explores the utility of diagnostic studies, operations and postoperative complications.

Methods Medline and PubMed database(s) were searched for ALL studies reporting H-TEF during 1997-2020. Using PRISMA methodology, manuscripts were screened for eligibility and reporting.

Results Forty-seven eligible studies were analysed. Primary diagnosis varied widely with surgeons performing oesophagography and trachea-bronchoscopy. Preoperative localisation techniques included fluoroscopy, guidewire placement and catheterisation. A cervical approach (209 of 272 cases), as well as thoracotomy, thoracoscopy and endoscopic fistula ligation, were all described. Morbidity included fistula recurrence (1.7\%), leak (2\%), tracheomalacia (3.4\%) and respiratory sequelae $(1 \%)$. The major adverse complication in all studies was vocal cord palsy secondary to laryngeal nerve injury (18.5\%) yet strikingly few centres routinely reported undertaking vocal cord screening pre or postoperatively.

Conclusion This study shows that paediatric surgeons record low volume activity with H type tracheoesophageal fistula. Variation(s) in clinical practice are widely evident. Laryngeal nerve injury and its subsequent management warrant special consideration. Care pathways may offset attendant morbidity and define 'best practice.'
\end{abstract}

Keywords $\mathrm{H}$ type tracheoesophageal fistula $\cdot$ Congenital oesophageal anomaly $\cdot$ Clinical outcomes $\cdot$ Recurrent laryngeal nerve injury $\cdot$ Newborns $\cdot$ Paediatric

\section{Introduction}

Congenital tracheoesophageal fistulae are a rare developmental anomaly occurring in around 1 in 2500 live births [1]. The oesophageal malformation and its communication to the respiratory system are categorised into five distinct phenotypes. 'H-type', 'isolated or Gross' Type E' tracheoesophageal fistula is a very rare subtype accounting for $4-5 \%$

Supplementary Information The online version contains supplementary material available at https://doi.org/10.1007/s0038 3-020-04853-3.

Paul D. Losty

paul.losty@liverpool.ac.uk

1 Department of Paediatric Surgery, Alder Hey Childrens' Hospital, Liverpool, UK

2 Institute of Child Health, School of Health And Life Science, University of Liverpool, Liverpool, UK of all congenital oesophageal malformations [1]. Patients with H-type fistula may present in the newborn period, infancy, childhood or even adulthood. Operation involving the identification of the fistula tract with the repair of the oesophagus and trachea is curative. Varied strategies are described to precisely localise the fistula and avoid damage to surrounding tissues. A systematic review of published studies was undertaken to explore contemporary surgical practice to benchmark outcomes for this very rare anomaly.

\section{Methods}

A systematic review was conducted in accordance with PRISMA guidelines [2]. A search using MEDLINE and PubMed databases for English articles published since January 1997 was performed. The following search terms were used: H-type fistula, isolated fistula and Gross type E fistula in isolation and association with tracheoesophageal fistula. 
Additional studies were identified through searching bibliographies and abstracts. The last search was performed in August 2020.

Inclusion criteria were articles reporting human studies on the diagnosis and management of congenital tracheoesophageal fistulae in the absence of oesophageal atresia. Eligible study design(s) included case report(s), case study series and review(s). The article selection process is outlined (Fig. 1). Articles were excluded after scrutinising the title and abstract if the studies were: not in humans and featured acquired or recurrent TEF. Only articles featuring diagnosis and management of patients under 16 years of age were considered, as this group most accurately represents the patient cohort of interest to paediatric surgeons. Full-text articles in which diagnosis, treatment, and follow up of H-type fistula were not discussed were omitted. Any diagnosis or management options relating to $\mathrm{H}$ fistula were considered.

Primary and secondary outcomes were extracted in each study. Primary outcomes included: (i) diagnosis, (ii) preoperative fistulae localisation, i.e. strategy deployed, (iii) operative approach and (iv) reporting of vocal cord injury as an adverse complication. Secondary outcomes were: (i) presenting symptoms, (ii) comorbidities, (iii) other complications and (iv) aftercare follow up.

\section{Results}

\section{Study description}

We identified 197 studies from the search through MEDLINE and an additional 15 reports from bibliography review. Fifty-seven full-text articles were reviewed, and a further ten papers were excluded where insufficient information was given on diagnosis or management. Forty-seven articles featuring a total of 342 patients met the full inclusion criteria. Unsurprisingly, given the rarity of $\mathrm{H}$ type tracheoesophageal fistula, most studies were case reports or small case series ( $<5$ patients) from single institutions. Fallon et al. [3] presented a large multicentre case series, including 102 patients over a 10 year study period [3]. Three reviews were included in the cohort; 2 reviews evaluated open 'classical' cervical vs thoracoscopic and endoscopic approaches and
Fig. 1 PRISMA flow chart with the literature search strategy

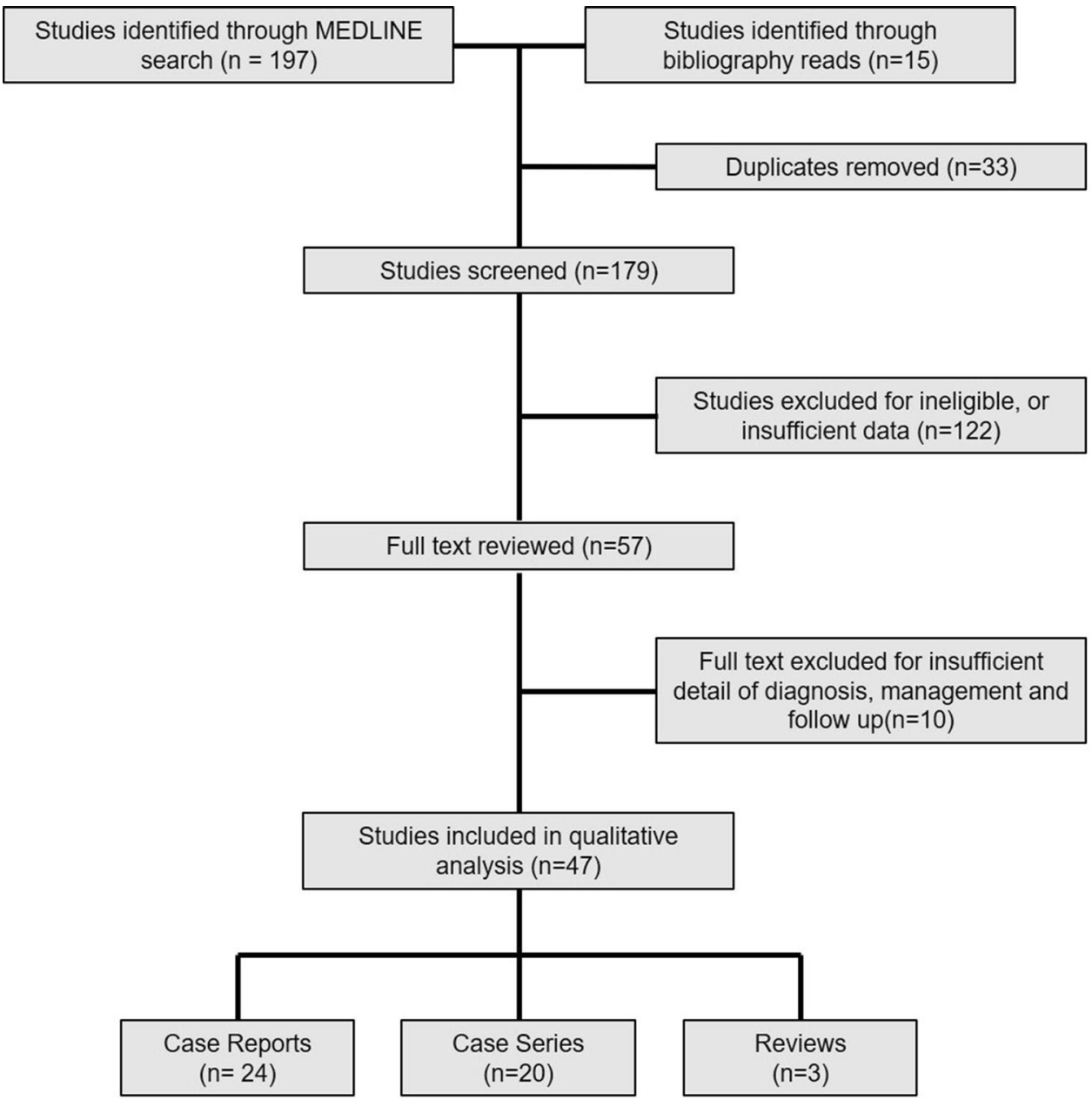


critical report analysis of $\mathrm{H}$-type fistulae from an anaesthetic perspective [4-6].

\section{Presentation}

High rates of co-associated anomalies were reported with H-type fistulae, with Daniel et al. noting 50\% of their cohort having another abnormality [5]. The most commonly reported anomalies were cardiac lesions, followed by allied disorders such as VACTERL syndrome (vertebral defects, anal atresia, cardiac defects, tracheoesophageal fistula, renal anomalies, and limb abnormalities) and CHARGE sequence (coloboma, heart defects, atresia choanae, growth retardation, genital abnormalities, and ear abnormalities). The range of comorbidities observed in these studies is highlighted in Table 1.

In some cases, co-existing pathology aided the prompt diagnosis of H-type fistula. Van Poll et al. cites an example of a vomiting newborn with suspected congenital oesophageal stenosis [7]. In this instance, the contrast swallow study highlighted not only oesophageal stenosis but also fortuitously a bronchogram image revealing an $\mathrm{H}$ type fistula. It should be noted that in many patients with life-threatening comorbidities, the subtler symptoms of H-type fistulae may be overlooked entirely. All index patients, regardless of age at diagnosis, will often have occult choking symptoms with feeds and recurrent respiratory infections from early childhood years. The more common presenting symptom in the infant may be linked with periods of apnoea and cyanosis. Although abdominal distension is described as a classic symptom of H-type fistula [1], only a small number of cases from this systematic review were identified and reported. Older patients may suffer for years with suspected gastrooesophageal reflux. In this review, 3 studies highlighted a delay in diagnosing H-type fistula in patients who had concurrent 'achalasia like symptoms'. In these cases, the $\mathrm{H}$ fistula lesion's operative repair dramatically improved symptoms of reflux and ameliorated oesophageal dysmotility $[8-10]$.

\section{Diagnosis}

Patient age at diagnosis ranged from a few days of life to 15 years. There were no cases of antenatal diagnosis. The majority of index cases may be detected as newborns; Fallon et al. recorded that $69 \%$ of patients were diagnosed in the first 30 days of life. Several other published studies show diagnosis at an older age group highlighting the difficulties that may identify this rare pathology. Investigations for H-type fistula aim to confirm the diagnosis and localise the level of the fistula to plan operative repair, e.g. cervical incision vs thoracotomy/thoracoscopy. Diagnostic investigations are broadly divided into radiological modalities such as contrast oesophagram or computed tomography (CT), or endoscopy - such as tracheoscopy. The overwhelming majority of patients underwent a contrast oesophagram as their first line of investigation. It should be noted however that $13 \%$ of patients who underwent a primary contrast oesophagram had an inconclusive investigation. Some of these patients went on to have a second and even a third contrast oesophagram confirm the diagnosis [11]. For a minority of patients, where there was a strong suspicion of H-type fistula despite 'reassurance' from a normal contrast swallow examination, a tracheoscopy or bronchoscopy was performed as a second-line investigation. In cases where an endoscopic approach was the first line of investigation but was inconclusive, a combination of tracheo-bronchoscopy and oesophagoscopy, either with or without the use of contrast was reported. Endoscopic studies also yielded false-negative results (2.6\%), typically within cases of newborns, where the fistula orifice may be small. Non-invasive diagnostic imaging such as high resolution computed tomography (CT) [9] or magnetic resonance imaging (MRI) [12] have also been utilised in preterm newborns and unstable patients (Fig. 2).

Table 1 Anomalies associated with H-type oesophageal atresia

\begin{tabular}{llllll}
\hline Associated anomalies (number reported) & & & & \\
\hline Cardiac & Trisomy & Syndromes & ENT & Gastrointesinal & Other \\
Unspecified cardiac (29) & Trisomy 21 (5) & VACTERL (7) & Tracheomalacia (3) & Oesophageal reflux (6) & Renal (26) \\
VSD (12) & Trisomy 18 (1) & CHARGE (4) & Laryngeal cleft (2) & Duodenal atresia (4) & Vertebral (22) \\
PFO (1) & Trisomy 13 (1) & Other non specified (2) & Choanal atresia (2) & Anorectal malformation (9) & Polydactyly (2) \\
PDA (4) & Unspecified (5) & & Cleft lip and palate (1) & Oesophageal stenosis (4) & Unspecified \\
& & & & &
\end{tabular}

Tetralogy of Fallot (4)

Auditory canal atresia (1) Exomphalos (1)

(4)

Coarctation of aorta (1)

Hypoplastic arch (1)

$V S D$ ventricular septal defect, $P F O$ patent foramen ovale, $P D A$ patent ductus arteriosus 


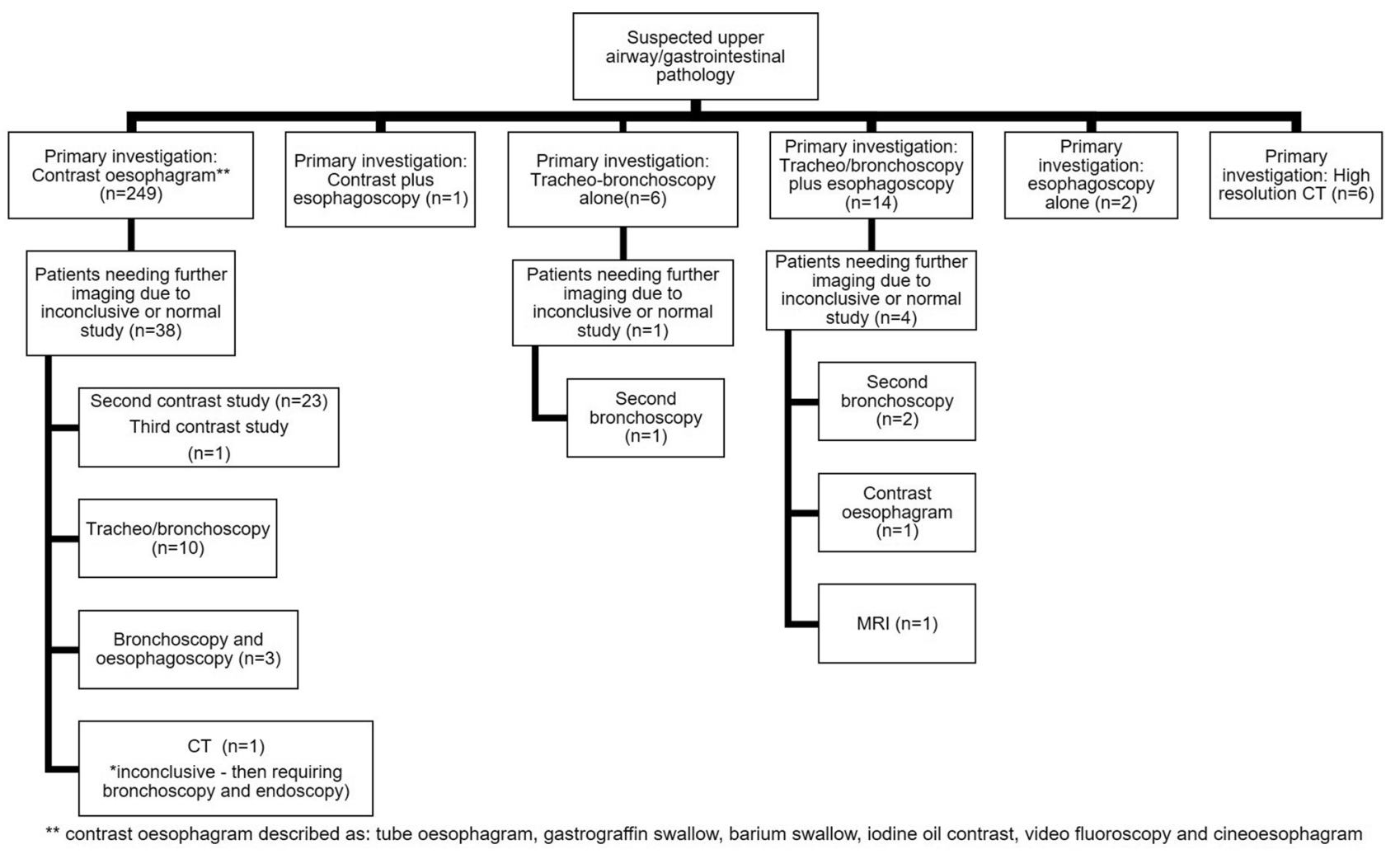

Fig. 2 Flowchart of the varied diagnostic pathways for $\mathrm{H}$ type oesophageal atresia

\section{Operative considerations}

Preoperative bronchoscopy and the fistula tract's cannulation were deployed accurately in over $75 \%$ of studies we analysed. Cannulation allows precise identification of the fistula tract intraoperatively. Many types of probe devices have been used to cannulate the fistula (Table 2). Steve Rothenberg presents the most extensive single-centre series of thoracoscopic operations. He states visualisation of the recurrent nerve(s) and the $\mathrm{H}$ fistula lesion is superior when performed thoracoscopically making cannulation of the tract not always necessary [13].

Identification and operative repair of the $\mathrm{H}$ fistula is curative. Many operative approaches are described. The classical right cervical incision with dissection of tissue planes in the root of the neck, isolation and repair of the defect is the most popular. The majority of $\mathrm{H}$ fistulae are located above the T2 level, thus allowing optimal access here. In cases of the fistulae lying unusually below T2 level, a thoracotomy or thoracoscopic repair was performed (Table 3).

Majority of studies describe a ligation of the fistula and non-tension closure of both oesophageal and tracheal sides with vicryl or PDS sutures. Al Salem describes a case where the fistula was transfixed only, and in this instance, the fistula reoccurred [11]. Tissue interposition (to offset recurrent fistula) between the oesophagus and trachea was well described in 7 studies. Sternothyroid, subhyoid and strap muscle as well as parietal pleural and fat flaps, are all discussed. Tsai and Zani independently describe deployment of tissue flaps for recurrent fistulae $[14,15]$. Insertion of wound drains was reported in only 7 studies. The majority here were small, non-suction devices exiting the cervical incision(s). One
Table 2 Probe devices used to cannulate $\mathrm{H}$ fistula preoperatively

\begin{tabular}{ll}
\hline Cannulation method & References \\
\hline Guidewire & Amat [13], Butterworth [14], De Schutter [15], Sim [16], Antao [17], Allal [18] \\
Fogarty & Aziz [19], Elebute [20], Riazulhaq [21] \\
Ureteric stent & Trobs [22] \\
Ureteric catheter & $\mathrm{Ng} \mathrm{[8],} \mathrm{Garcia} \mathrm{[23],} \mathrm{Rothenberg} \mathrm{[12]}$ \\
Bronchoscope & Tarcan [24], Goyal [25] we described fibreoptic illumination and entering the \\
& fistula with a 2.2 mm scope preoperatively as targeted identification \\
\hline
\end{tabular}


Table 3 Operative approaches to $\mathrm{H}$ fistula repair

\begin{tabular}{lr}
\hline Approach & $N$ \\
\hline Right cervical & 258 \\
Left cervical & 22 \\
Anterior cervical & 1 \\
Right thoracotomy & 10 \\
Thoracoscopic & 25 \\
Thoracoscopic converted to open & 5 \\
Endoscopic glue & 1 \\
Endoscopic YAG laser & 1 \\
Electrocautery (converted to open due to oesophageal injury) & 3 \\
\hline
\end{tabular}

chest drain was inserted with a thoracoscopy procedure, and a further single chest drain was placed on suction.

Ten studies, incorporating 16 patients, reported an MIS thoracoscopic approach for $\mathrm{H}$ fistula repair. (Table 4) Operative details were however clearly described in only 5 studies. Most surgeons here used a $5 \mathrm{~mm}$ telescope. The restricted operative field is often given as a reason not to perform this operation thoracoscopically. Despite this, only two centres used 30-degree scopes, with most utilising a 0-degree scope. The scope position sites were also highly variable, described as being in the anterior and mid-axillary lines, and anterior to the scapula. The time for the operative procedures was quoted as between 50-150 min; however, operation times were not provided in open cervical procedures as a comparator. Times to extubation ranged from 1-5 days and hospital discharge some 2-16 days postoperatively, which is similar to open cases, where reported. Two studies reported complications, notably a tracheal repair failure requiring a second open repair after the initial procedure and diaphragmatic paralysis and vocal cord injury. One thoracoscopic case was converted to an open operation.

Endoscopic ablation or ligation of $\mathrm{H}$ fistula was described in 4 studies. There are various modalities deployed: Cuestas et al. attempted sealing closure of the fistula tract using silver nitrate [16] . However, after 3 recurrences, the fistula was then operatively repaired. Bhatnagar used electrocautery alone in a 13-year-old patient, but again after 2 failed closures, this was corrected at open operation [17]. Tzifa described using electrocautery first, to de-epithelialise the fistula and promote scar formation, followed by applying histocryl glue, which was successful on its first attempt [18]. Of interest, this minimally invasive technique was performed on 2 patients with complete success and no long term complications.

\section{Postoperative management and complications}

The majority of patients in all reported studies were extubated within $48 \mathrm{~h}$ postoperatively (range 1 day-5 weeks). An oral contrast study was undertaken to exclude leak or recurrence of fistula in most but not all patients. Fallon reported that from some 102 patients, $78 \%$ had an oral contrast examination on day 7 postoperatively. Of that group, $8 \%$ ( $5 \%$ of the total cohort) were found to have a leak. Sim and Kane both reported a second fistula's discovery which went on to require further corrective surgery $[19,20]$. Stenosis of the oesophagus, either as a primary pathology or secondary to fistula repair was also noted and oesophageal dilatation(s) undertaken in symptomatic patients. [21] Rates of fistula recurrence in these patients were low, between 2-3\% of all cases reported. Mortality after $\mathrm{H}$ fistula operation in all reported studies was low. This occurred was often linked to other co-existent pathologies such as structural cardiac malformations or extreme prematurity. We observed 5 deaths $(1.7 \%)$ in all eligible reviewed studies [3, 12, 22].

The duration of hospital inpatient stay varied considerably depending on comorbidity(s) or other complications. Where no other pre-existent conditions prevailed, inpatient stay was typically between $2-10$ days.

The most frequently cited complication(s) with $\mathrm{H}$ fistula's operative repair was vocal cord injury and gastro-oesophageal reflux. Vocal cord dysfunction may be typically unilateral or bilateral with patients having pronounced hoarseness, feeding difficulty and recurrent pneumonia(s). Fallon et al. strikingly reported that some $22 \%$ of patients had vocal cord injury [3]. However, only one-third of all patients here had formal postoperative laryngoscopy examinations with vocal cord assessment, and so morbidity may be much higher than that reported. Fung and Zani both observed 50\% vocal cord dysfunction rates in their studies [15, 23]. There is little data regarding congenital vocal cord paralysis. Indeed, there is a case to be made for preoperative assessment of function to reflect iatrogenic operative injury rates accurately [24]. From the eligible publications we scrutinised, the majority of patients showed degrees of resolution without intervention. Tracheostomies were undertaken and reported in 2 studies to provide patients with a safe patent airway $[3,25]$.

Gastroesophageal reflux may be observed in patients with co-existent $\mathrm{H}$ type fistula, and in some cases, this alone may lead to a delay in primary diagnosis. Here of interest, a fundoplication was performed in $25(8.7 \%)$ patients with $\mathrm{H}$ fistula. Timing of anti-reflux surgery was variably reported with some fundoplication operations undertaken before $\mathrm{H}$ fistula repair then leading to the 'late' diagnosis of the anomaly and others repaired concurrently.

Aftercare follow up visits after H-TEF repair where reported ranged from 3 months -9 years. 


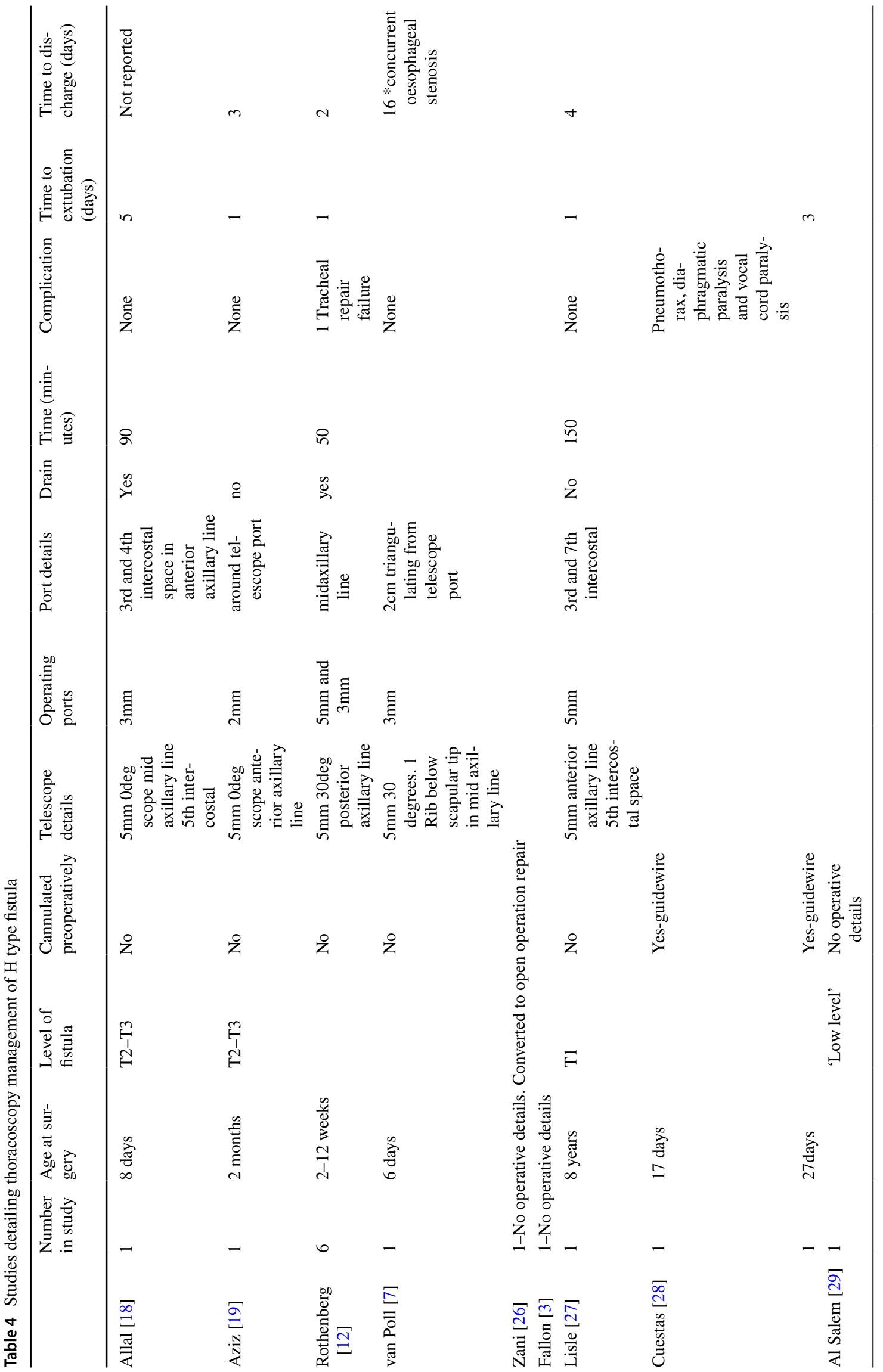




\section{Discussion}

$\mathrm{H}$ type tracheoesophageal fistula without oesophageal atresia is a rare entity seen in 1 in 50,000 to 80,000 live births and accounts for $4-5 \%$ of all congenital oesophageal anomalies [1]. Patients with this rare condition may not always be diagnosed in the immediate newborn period. Late diagnosis may occur as the newborn can feed with subtle airway aspiration features, and recurring chest infections may be erroneously attributed to gastrooesophageal reflux. In this systematic review of all eligible published studies, it was apparent that the well-described triad of classic symptoms notably-abdominal distension, respiratory infection(s), choking and cyanosis on feeding, are not always specific enough to lead to early primary diagnosis. Delay in diagnosis may portend severe morbidities, like that reported in the 15-year-old patient described by Boybeyi et al. This late case presented with irreversible lung damage after years of occult aspiration and chest infection(s) [9]. Late or missed diagnosis may also be due (in part) to the variable anatomy of the fistula. A small and narrow fistula tract may be overlooked on the initial investigation(s), especially in older children where the oesophagus' mucosal folds may act intermittently as a 'protective valve' [30]. Thirteen per cent of all primary investigations were falsely negative in this comprehensive systematic review of the literature. There is no single investigation with sufficient sensitivity and specificity to aid ready accurate diagnosis of $\mathrm{H}$-type fistula. However, a diagnostic algorithm which may improve detection rates should include a dynamic prone contrast oesophagram along with a tracheo-bronchoscopy study for precise localisation [26]. Non-invasive imaging, notably CT and MRI, are perhaps best reserved for the extreme preterm newborn where small patient size precludes airway instrumentation and endoscopy.

Preoperative, awake tracheo-bronchoscopy as a diagnostic tool allows ready identification of the fistula, assessing vocal cord motility, and evaluating other concurrent pathology, such as tracheomalacia [3]. Airway endoscopy facilitates fistula tract cannulation and its bright field 'illumination' guiding the surgeon intraoperatively [27].

Identifying the level of the fistula is crucial as this dictate operative approach. Three-quarters of isolated $\mathrm{H}$ fistulae are located at the T2 vertebra level or above [4]. Here a trans-cervical approach offers optimal access. Genty has outlined that a surgeon's preference may dictate their clinical practice: with paediatric surgeons often employing a right cervical incision vs a left cervical incision used by the ENT specialist [29]. Fistulae located below the level of $\mathrm{T} 2$ are most commonly accessed either open via a thoracotomy or thoracoscopy [28] Enthusiasts for thoracoscopic repair argue that there is wholly adequate visualisation and access to the $\mathrm{H}$ fistula lesion without the morbidity associated with thoracotomy such as winging of the scapulae or scoliosis. In a systematic review of thoracoscopy cases, Parolini et al. described a handful of case report(s) and cohort series' with considerable variability in patient positioning, instrumentation, operating time(s) and postoperative recovery [4] There remains only a few case series' of thoracoscopic cases. So, whether there is a real advantage in utilising thoracoscopy over an open approach remains open to debate. However, as surgeons' numbers using a thoracoscopic approach increases, new, more robust data may guide future practice. Endoscopic closure of $\mathrm{H}$ fistulae has been reported with varied techniques such as tissue glue adhesives, electrocautery, sclerosant agents and laser ablation. Although these may be theoretically appealing as much less invasive methods, there appears to be higher rate(s) of fistula recurrence in these published studies [5].

The most commonly reported associated morbidity(s) with $\mathrm{H}$ fistula operation are gastroesophageal reflux and vocal cord injury. Although dysphagia and reflux are much more frequently seen in patients with other variant lesions within the spectrum of oesophageal atresia, a cohort of patients with isolated $\mathrm{H}$ type fistula experienced medically resistant reflux underwent anti-reflux surgery [1] Lemoine describes intrinsic oesophageal dysmotility in patients with $\mathrm{H}$ fistulae before undergoing operative correction [31] In this systematic review, we found three recorded $\mathrm{H}$ fistula cases associated with congenital oesophageal stenosis and achalasia symptoms. This suggests that although the $\mathrm{H}$ fistula lesion may appear to be the predominant anatomical defect, there is likely a spectrum of variant pathology observed with oesophageal anomalies and H-type fistula.

Vocal cord injury (up to $18.5 \%$ index cases) is a major adverse complication after $\mathrm{H}$ fistula repair. It may present as an acute or chronic airway problem in the absence of fistula recurrence. For some patients, vocal cord injury may lead to unsafe swallow necessitating modification of feeds, or use of feeding tubes. Most significantly bilateral vocal cord injury may lead to a compromised airway, requiring definitive management with a tracheostomy. Despite being recognised as a not infrequent and a serious complication associated with H-TEF repair, very few institutions routinely screen for vocal cord injury postoperatively. Zani et al. reported that while such symptoms may resolve, it is concerning that only one-third of all patients with vocal cord injury after $\mathrm{H}$ fistula operation regained normal vocal cord function in aftercare follow up. The Toronto group now advocate a multidisciplinary care team to include ENT surgeons in the long term follow-up and monitoring of these patients [15]. Parents should, therefore, always receive accurate preoperative counselling by the operating surgeon detailing the risk(s) of recurrent laryngeal nerve 
injury together with fistula recurrence when scheduling operation.

We fully acknowledge that this systematic review study has limitations. The eligible studies were all retrospective and for the most part cohort series or case report(s), reflective of the rare incidence of $\mathrm{H}$ type tracheo-oesophageal fistulae. Also, there is a variation in the diagnostic, management and follow up outcomes reported. Nonetheless, we fully report the utility of various diagnostic studies, care pathway algorithms and outcome metrics from the quality of the published literature available.

In closing, we believe this study helpfully provides paediatric surgeons with collective informative metrics allowing them to benchmark their own clinical outcome(s) and performance when operating on patients with rare $\mathrm{H}$ type tracheoesophageal anomalies.

Open Access This article is licensed under a Creative Commons Attribution 4.0 International License, which permits use, sharing, adaptation, distribution and reproduction in any medium or format, as long as you give appropriate credit to the original author(s) and the source, provide a link to the Creative Commons licence, and indicate if changes were made. The images or other third party material in this article are included in the article's Creative Commons licence, unless indicated otherwise in a credit line to the material. If material is not included in the article's Creative Commons licence and your intended use is not permitted by statutory regulation or exceeds the permitted use, you will need to obtain permission directly from the copyright holder. To view a copy of this licence, visit http://creativecommons.org/licenses/by/4.0/.

\section{References}

1. Crabbe DC (2003) Isolated tracheo-oesophageal fistula. Paediatr Respir Rev 4:74-78. https://doi.org/10.1016/S1526

2. Moher D, Liberati A, Tetzlaff J, Altman DG (2010) Preferred reporting items for systematic reviews and meta-analyses: the PRISMA statement. Int J Surg 8:336-341. https://doi. org/10.1016/j.ijsu.2010.02.007

3. Fallon SC, Langer JC, Peter SD, Tsao KJ, Kellagher CM, Lal DR et al (2017) Congenital H-type tracheoesophageal fistula: a multicenter review of outcomes in a rare disease. J Pediatr Surg 52:1711-1714. https://doi.org/10.1016/j.jpedsurg.2017.05.002

4. Parolini F, Morandi A, Macchini F, Gentilino V, Zanini A, Leva E (2014) Cervical/thoracotomy/thoracoscopic approaches for H-type congenital tracheo-esophageal fistula: a systematic review. Int J Pediatr Otorhinolaryngol 78:985-989. https://doi.org/10.1016/j. ijporl.2014.04.011

5. Daniel SJ, Smith MM (2016) Tracheoesophageal fistula: open versus endoscopic repair. Curr Opin Otolaryngol Head Neck Surg 24:510-515. https://doi.org/10.1097/MOO.0000000000000315

6. Edelman B, Selvaraj BJ, Joshi M, Patil U, Yarmush J (2019) Anesthesia practice: review of perioperative management of H-type tracheoesophageal fistula. Anesthesiol Res Pract. https://doi. org/10.1155/2019/8621801

7. Van Poll D, Van Der Zee DC (2012) Thoracoscopic treatment of congenital esophageal stenosis in combination with H-type tracheoesophageal fistula. J Pediatr Surg 47:1611-1613. https:// doi.org/10.1016/j.jpedsurg.2012.05.015

8. Ng J, Bartram J, Antao B, Everard M, Shawis R (2006) H-type tracheoesophageal fistula masquerading as achalasia cardia in a 13-year-old child. J Paediatr Child Health 42:215-216. https://doi. org/10.1111/j.1440-1754.2006.00833.x

9. Boybeyi Ö, Köse M, Ersöz DD, Haliloglu M, Karnak I, Şenocak ME (2008) Achalasia-like findings in a case with delayed diagnosis of H-type tracheoesophageal fistula. Pediatr Surg Int 24:965 969. https://doi.org/10.1007/s00383-008-2192-y

10. Singh S, Wakhlu A (2012) Megaesophagus in the pediatric age group: a diagnostic dilemma. Saudi J Gastroenterol 18:151-152. https://doi.org/10.4103/1319-3767.93827

11. Al-Salem AH, Mohaidly MA, Al-Buainain HMH, Al-Jadaan S, Raboei E (2016) Congenital H-type tracheoesophageal fistula: a national multicenter study. Pediatr Surg Int 32:487-491. https:// doi.org/10.1007/s00383-016-3873-6

12. Gunlemez A, Anik Y, Elemen L, Tugay M, Gökalp AS (2009) $\mathrm{H}$-type tracheoesophageal fistula in an extremely low birth weight premature neonate: appearance on magnetic resonance imaging. J Perinatol 29:393-395. https://doi.org/10.1038/ jp. 2008.198

13. Rothenberg SS (2018) Thoracoscopic management of non-type $C$ esophageal atresia and tracheoesophageal atresia. J Pediatr Surg 53:121-125. https://doi.org/10.1016/j.jpedsurg.2017.10.025

14. Tsai JY, Berkery L, Wesson DE, Redo SF, Spigland NA (1997) Esophageal atresia and tracheoesophageal fistula: Surgical experience over two decades. Ann Thorac Surg 64:778-783. https://doi. org/10.1016/S0003-4975(97)00752-2

15. Zani A, Jamal L, Cobellis G, Wolinska JM, Fung S, Propst EJ et al (2017) Long-term outcomes following H-type tracheoesophageal fistula repair in infants. Pediatr Surg Int 33:187-190. https://doi. org/10.1007/s00383-016-4012-0

16. Cuestas G, Rodríguez V, Millán C, Munzón PB, Munzón GB (2020) H-type tracheoesophageal fistula in the neonatal period: difficulties in diagnosis and different treatment approaches. A case series. Arch Argent Pediatr 118:56-60. https://doi.org/10.5546/ AAP.2020.ENG.56

17. Bhatnagar V, Lal R, Sriniwas M, Agarwala S, Mitra DK (1999) Endoscopic treatment of tracheoesophageal fistula using electrocautery and the Nd:YAG laser. J Pediatr Surg 34:464-467. https ://doi.org/10.1016/s0022-3468(99)90500-6

18. Tzifa KT, Maxwell EL, Chait P, James AL, Forte V, Ein SH et al (2006) Endoscopic treatment of congenital H-Type and recurrent tracheoesophageal fistula with electrocautery and histoacryl glue. Int J Pediatr Otorhinolaryngol 70:925-930. https://doi. org/10.1016/j.ijporl.2005.10.017

19. Sim J, Hong J (2018) Double H-type tracheoesophageal fistulae: a case report. Adv Pediatr Surg. https://doi.org/10.13029/ aps.2018.24.2.94

20. Kane TD, Atri P, Potoka DA (2007) Triple fistula: management of a double tracheoesophageal fistula with a third $\mathrm{H}$-type proximal fistula. J Pediatr Surg 42:10-12. https://doi.org/10.1016/j.jpeds urg.2006.11.009

21. Babu R, Hutton KAR, Spitz L (2005) H-type tracheo-oesophageal fistula with congenital oesophageal stenosis. Pediatr Surg Int 21:386-387. https://doi.org/10.1007/s00383-004-1343-z

22. Conforti A, Iacusso C, Valfrè L, Trozzi M, Bottero S, Bagolan P (2016) Cervical repair of congenital tracheoesophageal fistula: complications lurking! J Pediatr Surg 51:1623-1626. https://doi. org/10.1016/j.jpedsurg.2016.06.010

23. Fung SW, Lapidus-Krol E, Chiang M, Fallon EM, Haliburton B, Propst EJ et al (2019) Vocal cord dysfunction following esophageal atresia and tracheoesophageal fistula (EA/TEF) repair. J Pediatr Surg 54:1551-1556. https://doi.org/10.1016/j.jpeds urg.2018.08.041 
24. Mortellaro VE, Pettiford JN, St Peter SD, Fraser JD, Ho B, Wei J (2011) Incidence, diagnosis, and outcomes of vocal fold immobility after esophageal atresia (EA) and/or tracheoesophageal fistula (TEF) repair. Eur J Pediatr Surg. https://doi. org/10.1055/s-0031-1291269

25. Antao B, Soccorso G, Bateman N, Shawis R (2007) H-type tracheoesophageal fistula with type III laryngotracheoesophageal cleft. Eur Arch Oto-Rhino-Laryngol 264:1373-1376. https://doi. org/10.1007/s00405-007-0356-3

26. Losty Paul D et al (2018) Rickham's Neonatal Surgery. Springer, London. https://doi.org/10.1007/978-1-4471-4721-3

27. Goyal A, Potter F, Losty PD (2005) Transillumination of H-type tracheoesophageal fistula using flexible miniature bronchoscopy: an innovative technique for operative localisation. J Pediatr Surg 40:33-34. https://doi.org/10.1016/j.jpedsurg.2005.03.029

28. Dai J, Pan Z, Wang Q, Wu Y, Wang J, Wang G et al (2018) Experience of diagnosis and treatment of $31 \mathrm{H}$-type tracheoesophageal fistula in a single clinical center. Pediatr Surg Int 34:715-719. https://doi.org/10.1007/s00383-018-4293-6
29. Genty E, Attal P, Nicollas R, Roger G, Triglia JM, Garabedian EN et al (1999) Congenital tracheoesophageal fistula without esophageal atresia. Int J Pediatr Otorhinolaryngol 48:231-238. https:// doi.org/10.1016/S0165-5876(99)00039-7

30. Blackburn WR, Amoury RA (2020) Congenital esophago-pulmonary fistulas without esophageal atresia: an analysis of 260 fistulas in infants, children and adults. Rev Surg 23:153-175

31. Lemoine C, Aspirot A, Morris M, Faure C (2015) Esophageal dysmotility is present before surgery in isolated tracheoesophageal fistula. J Pediatr Gastroenterol Nutr 60:642-644. https://doi. org/10.1097/MPG.0000000000000667

Publisher's Note Springer Nature remains neutral with regard to jurisdictional claims in published maps and institutional affiliations. 